Natural Hazards and Earth System Sciences (2004) 4: 485-499

SRef-ID: 1684-9981/nhess/2004-4-485

(C) European Geosciences Union 2004

\title{
Multi-criteria decision model for retrofitting existing buildings
}

\author{
M. D. Bostenaru Dan \\ Institute for Technology and Management in Construction, Am Fasanengarten, Geb. 50.31, University of Karlsruhe, D-76128 \\ Karlsruhe, Germany
}

Received: 30 September 2003 - Revised: 9 June 2004 - Accepted: 5 July 2004 - Published: 18 August 2004

\begin{abstract}
Decision is an element in the risk management process. In this paper the way how science can help in decision making and implementation for retrofitting buildings in earthquake prone urban areas is investigated. In such interventions actors from various spheres are involved. Their interests range among minimising the intervention for maximal preservation or increasing it for seismic safety. Research was conducted to see how to facilitate collaboration between these actors. A particular attention was given to the role of time in actors' preferences. For this reason, on decision level, both the processural and the personal dimension of risk management, the later seen as a task, were considered. A systematic approach was employed to determine the functional structure of a participative decision model. Three layers on which actors implied in this multi-criteria decision problem interact were identified: town, building and element. Socalled 'retrofit elements' are characteristic bearers in the architectural survey, engineering simulations, costs estimation and define the realms perceived by the inhabitants. This way they represent an interaction basis for the interest groups considered in a deeper study. Such orientation means for actors' interaction were designed on other levels of intervention as well. Finally, an 'experiment' for the implementation of the decision model is presented: a strategic plan for an urban intervention towards reduction of earthquake hazard impact through retrofitting. A systematic approach proves thus to be a very good communication basis among the participants in the seismic risk management process. Nevertheless, it can only be applied in later phases (decision, implementation, control) only, since it serves verifying and improving solution and not developing the concept. The 'retrofit elements' are a typical example of the detailing degree reached in the retrofit design plans in these phases.
\end{abstract}

Correspondence to: M. D. Bostenaru Dan

(bostenaru@tmb.uni-karlsruhe.de)

\section{Introduction}

Risk management is a process including all or some steps like identification, assessment, mitigation, monitoring, review and communication of risks resulting from a certain hazard on a site or an activity. It involves making and implementing decisions to minimise the adverse effects from hazards impact. Between risk assessment and mitigation spans the field of risk exposure analysis and evaluation of risk 'treatment' strategies. The prioritisation process in risk management also relies to an important extent on the communication between the actors assessing risk and setting priorities, as better communication enables the development of more efficient strategies to manage the risk through more appropriate decisions.

In case of preventive risk management the amount of action towards damage reduction depends on the availability and usability of information at a given time. GIS systems, various knowledge bases in the internet and expert systems, to name a few, are important to cover information needs of both experts and laics. Experts can be natural and social scientists, engineers and planners in the pre-disaster phase and emergency managers post-disaster. Laics can be passive public in pre-disaster phase and affected people post-disaster. Such visualisation means enable them to communicate using a common base and are also useful to communicate figures to decision makers.

In case of a risk mitigation measure taking the form of a construction, the (drawn) plans of a project express its objectual dimension and the planning, as function of project management, its processural dimension. The understanding of building and urban planning changed over time and this change was particularly fast in the last 40 years (Bostenaru, 2004). Theoretical and empirical models have been developed in order to design 'communicative' planning processes. 'Communication' builds in this case the successor of the 'participation', which supposed a central decision process inside the political-administrative system, to which third parties could participate within the frame 
of information processes. Communication enlarges the codesigning possibilities with several processes, from which co-operation between involved actors is the most important. Through co-operation the decision process is relocated in independent fields outside politics and administration and the reality of simultaneous decision processes is accepted. In the meantime a transition took place: from traditional offer planning, relying on absolute values, one element in the management process, to strategic planning, which includes implementation and control, and thus all management stages. The systematic understanding of planning is a result of a strategic approach to it (Bostenaru, 2002). Joedicke's view (1976) can be put into this context. He defines planning as a systematically made development and decision process for preparation of actions, with help of which societal scopes can be formulated and action programmes can be implemented. The project and the goal definition are seen by Joedicke (1976) as a parallel flow. Strategic planning, a process oriented approach towards the organisation of urban possibilities, is less oriented against products or results and is instead a social action and learning process, within which the potential actors are developing. Relevant participative/communicative planning models along the time are (Bostenaru, 2004):

- the "pattern language" of Alexander (1977), developed in the 60s. Impressive spatial situations show similar "patterns", which constitute the elements of a language "for all citizens", defined spatially and functionally in a cybernetic way;

- the construction research performed by Ottokar Uhl and his team after applying the Stichting Architectural Research method (Habraken, 1973) for the project "Wohnen morgen" in Hollabrunn, Austria, in the 70s (Hempel and Uhl, 1982). A learning process was initiated parallel to the construction process, this involving both "affected people" (Hempel and Uhl, 1982) and "experts" (Fingerhuth and Koch, 1996) to a different extent at certain stages of decision making;

- building modernisation support schemes in the 80s, such as Private-Public-Partnerships on local scale, neighbourhood supports and co-operation nets, as first examples of communication. An example for the decision models applied that time is given by the approach adopted in the restoration of the Weissenhof Siedlung in Stuttgart, Germany (Nägele, 1992), to solve the tensions between those involved in conservation of historic buildings, construction technique, construction financing and respectively user interests;

- interdisciplinary co-operation in the 90s. Involved actors have the possibility to be trained about the way of approach and the vocabulary of the disciplines with which they collaborate. A programme exists before approaching the problem, for example in form of a manual like ATC-40 (Comartin et al., 2000). The result is an unique conclusion, where the components orig- inating from a discipline or another (in case of ATC40: building owners and agency representatives, architects, building officials, structural engineers and analysts) cannot be distinguished anymore;

- innovative co-operative approaches today, like "Planning through Projects" (IBA, 1999) in construction exhibitions in order to address new tasks or in virtual cooperation networks on the world wide web in order to address new technologies. While GIS technologies are useful in visualisation, full use of internet communication allows a more efficient disaster risk management through dynamic exchange of information and communication. The later is exemplified by the World Housing Encyclopedia (EERI, 2004), an information database to be shared by all those interested in seismic resistant housing construction.

The author developed the concept of 'retrofit elements' as suitable "pattern" for the inter-disciplinary problem 'retrofitting historic buildings'. Such elements are the communication basis for interest groups on conservation of historic buildings, structural behaviour and construction techniques, construction costs and, more limited, user interests. This way key actors in the decision process are pre-figured: the architect, the civil engineer, the investor and the user. The views of these actors will be regarded further in this paper.

Closest to the idea of this study lay the objectives and achievements of the RISK-UE Project (Mouroux et al, 2004). This joint endeavour involved the assessment of earthquake risk scenarious in seven European cities in order to provide decision makers and disaster managers with estimates on seismic hazard impact. Aimed were increasing awareness on city decision making level and to initiate seismic risk appropriation on all levels (see an example in RISK-UE, 2004). To the strategic objectives belonged developing GIS urban databases as a decision making tool. Other two objectives concern the dissemination of results and international networking. But the most innovative one addresses the sensibilisation of city actors by means of earthquake impact assessment, according to which action plans would be elaborated. The project is expected to have impact on the "development within the cities of services specialised in taking account of these risks in order to establish 'Risk Management Plans' and 'Action Plans' in the short, medium and long term." (Mouroux et al., 2004).

It is the object of the impact assessment which essentially distinguishes the aim of this paper of that of the RISK-UE project. Not the earthquake impact is in question, but the impact of the preventive intervention on buildings in order to reduce the damaging effect of earthquake events. Aim of the paper is to develop communication structures for decision makers involved in retrofitting existing buildings and to analyse how language patterns developed at different spatial scales flow into. It starts from casting the model into the generic framework of multi-criteria decision analysis and closes with an implementation strategy model based on the multilevel interaction at various scales. Strategic planning 


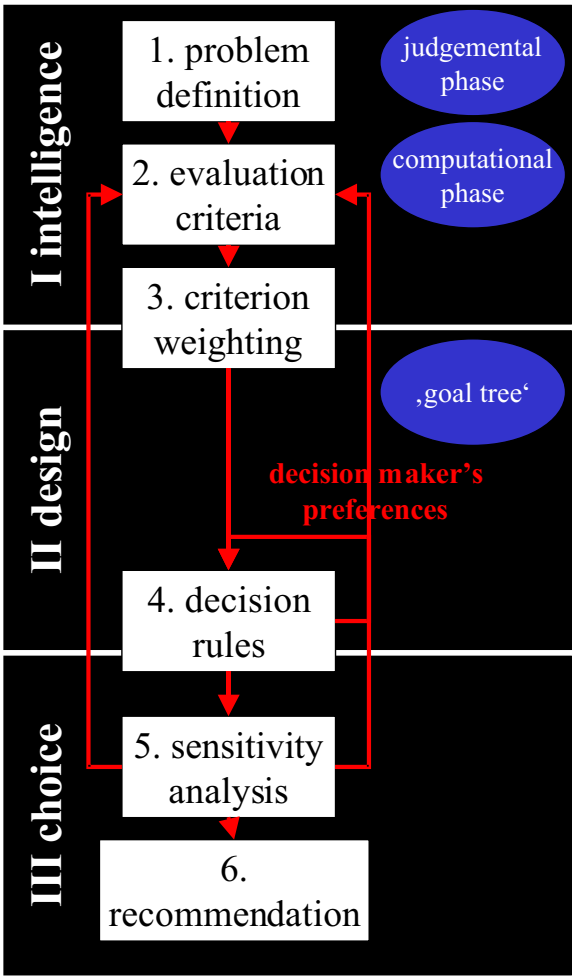

Fig. 1. Flow chart for the spatial multi-criteria decision analysis. It shows the two layouts proposed by Malczewski (1999), in six (Arabic numbers) and respectively three (Roman numbers) steps highlighting the stages at which specific approaches have been developed by the author of this paper.

for urban earthquake risk mitigation will be exemplified, and represents the model for decision implementation. Outgoing point is the impact assessment practice in urban planning (impact assessment is carried out for each new development), as image of the development and orientation for the interaction between the planning levels and the participating actors. The focus lays on the planning intervention for preparedness and not in emergency management.

\section{Nature of spatial multi-criteria decision support}

Malczewski (1999) provided in his book "GIS and Multicriteria Decision Analysis" an extensive state-of-the-art review of multi-criteria decision systems for spatial problems. Malczewski (1999) proposes two different layouts for the decision making: a three-phases one and a detailed step-wise one. These three phases in the process are called "intelligence", "design" and "choice". The steps to be followed, namely problem definition, evaluation criteria, criterion weighting, decision rules, sensitivity analysis and finally recommendation, can be assigned to the phases as shown in Fig. 1.

The intelligence phase encompasses the problem statement, the selection of the evaluation criteria and the selection of the criterion weighting type. Problem statement means in Malczewski's approach the modelling of the spatial object, which facilitates identifying spatial decisions, and the identification of the actors. The first implies converting data to information. The identified spatial elements are variables in a multi-attributive decision making (with attributes as constrains). Evaluation criteria are attributes, indicating to which degree preferences of the actors are achieved. Malczewski (1999) reviews several methodologies for creating a hierarchical value structure for purposes of criterion weighting, which is a preferences structure modelling technique. According to Malczewski (1999) GIS is useful in "preference elucidation and aggregation", the way he calls interactively setting the priorities with use of visualisation techniques. It includes a judgemental phase and computational phase, through which suitable variants are selected and thus the options reduced from the very begin in the intelligence phase. Two criterion weighting rules of those reviewed by Malczewski are of special interest: the pair wise comparison method of Saaty (1980) and the rating method, often concretised in the utility value approach.

Design means generating alternatives. This phase consists of a single, but comprehensible step: the selection of the decision rule type. Decision rules strongly depend on the conflicting preferences of the actors. Malczewski (1999) proposes an expert system based choice of the decision rule(s). Selection factors are the characteristics of the decision rule, of the decision makers and of the decision problem as well as the size of the problem. There is an interdependency between the size of the problem and the criteria adopted. The criteria are, on their part, influenced by the adopted decision rule (Fig. 1). Thus the selection is also influenced by factors like the number of criteria, of alternatives and of constraints. Computer interaction depends on the degree of structuring of the problem. Malczewski (1999) proposes for this to select a decision support system, out of a toolbox (a methodology for creating a multi-criteria value structure), an interface and a database. The toolbox contains the actors' preferences based on criterion weighting, generating and evaluating alternatives and the choice. The database, which can be also a model-base is derived in this phase to a knowledgebase. Malczweski (1999) closes describing an issue met in building decision support systems: the integration of spatial decision support systems with spatial expert systems.

The last phase in solving the decision problem is the choice. It comprises the evaluation of alternatives and issuing of recommendation. The sensitivity analysis undertaken in this phase is seen as a learning process in which the decision makers are repeatedly confronted with the structure of the problem. Input variations such as changes in the spatial data or in the actor's preferences are influencing the ranking of the alternatives in the choice (Fig. 1). Decision makings techniques as well as visualisation and data administration techniques (such as GIS) are involved equally in this final phase. The implementation of one or several alternatives can be recommended. 


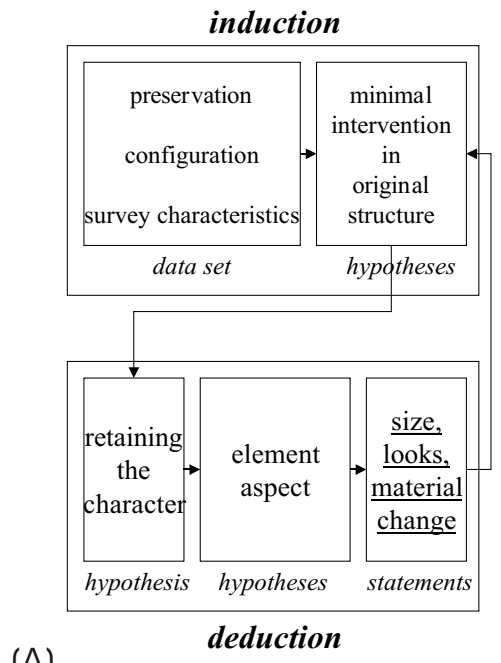

$(A)$

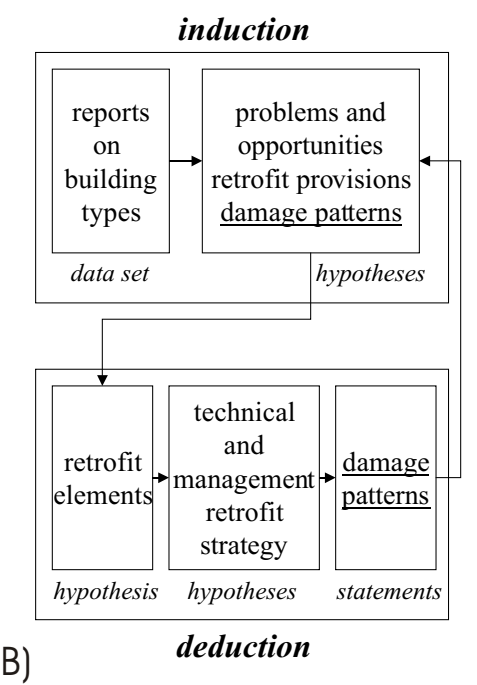

Fig. 2. Regression for determining the goals of the architect (a) and the criteria concerning the retrofit elements (b). For both data sets are obtained from case studies and the hypothesis for the decision tree induced. From these individual hypotheses a single hypothesis is obtained, to be integrated into the mission/recommendation. Then hypotheses for the individual elements are derived and finally statements about them deducted. These statements are feedback compared with the induced hypothesis in order to regressively reformulate the later.

\section{Multi-criteria decision making}

Decision is an element in a management process. Risk management is such a process, for which decisions are control options in mitigation/response operations. Consequently risk management builds on the task related understanding of management. Task related management shows several dimensions. Such a dimension is the processural one, in which case the management elements are functions like planning, decision, implementation and control. In the structural dimension management is seen from the technical side, and organisational and operational structures count to its instru- ments. Along the personal dimension management is seen as a system and relates to the kinds of leadership employed, like participative/co-operative versus authoritative style. For the purpose of building decision making and implementing models, the personal dimension has been taken into consideration by modelling a participative system for multi-criteria decisions. A system can be also seen from alternative perspectives: as an object or as a process (Bostenaru, 2002). Procesurally defined, a system is the organisation form of all material or ideal elements, which stay in an interaction relationship one to another and belong to a functional whole. For decision making the systematic approach itself is relevant. In a systematic approach, an optimal system has to be found for each criterion and group of actors. A cybernetic analysissynthesis approach was employed. This requires building models of these systems according to their descriptions and the related insights.

Joedicke (1976) analysed in his work techniques useful in building planning with emphasis on decision related aspects. The usage of some of these techniques gives adequate instruments for a systematic decision. Such one is an approach where characteristics and criteria are deducted based on analysis of existing projects, while know-how is derived by means of scientific disciplines. In this work, decision trees were modelled by regressive means using a related approach (Fig. 2). Knowledge about the interest groups to be considered and their preferences was induced from the participative case studies. The obtained hypothesis concerned the functional structure for decision making. Goals for each actor were formulated on each level of intervention. In the first step of the deductive phase a general hypothesis had to be drawn out from the one formulated after induction. In a second step statements for a particular case can be derived. Such an experiment was the retrofit of reinforced concrete frame buildings (Table 1).

In each decision tree developed (called in this work 'goal tree'), weights were set to measurable criteria (Figs. 3a, c-e). Weights were estimated while simulating a group decision making through a multi-criteria one, each actor corresponding to a criterion. They were assigned according to the importance of the criterion, the reliability of the values measuring the criterion achievement degree, and the degree to which the judgement of a certain actor is relevant for a certain characteristic. The relative weight results from the multiplication of the weight of the goal and the weight of the sub-goal. The sum of all goal weights remains $1(100 \%)$. Goals are related to characteristics, they represent a desirable value of a characteristic regarding a certain criterion. Figure $3 b$ shows a step in the score assignment, namely defining the measurement spaces for the criteria. For example, the first group of criteria relevant for the structural engineer concern the vulnerability, set on urban scale. These are the design earthquake for the retrofit measure, which is influenced by its periodicity and maximal intensity. Rapid visual screening allows (FEMA, 1988) for setting scores for categories of buildings, the typology of which is given by the construction material. It can be clearly seen that the group of engineering criteria 'retrofit' 

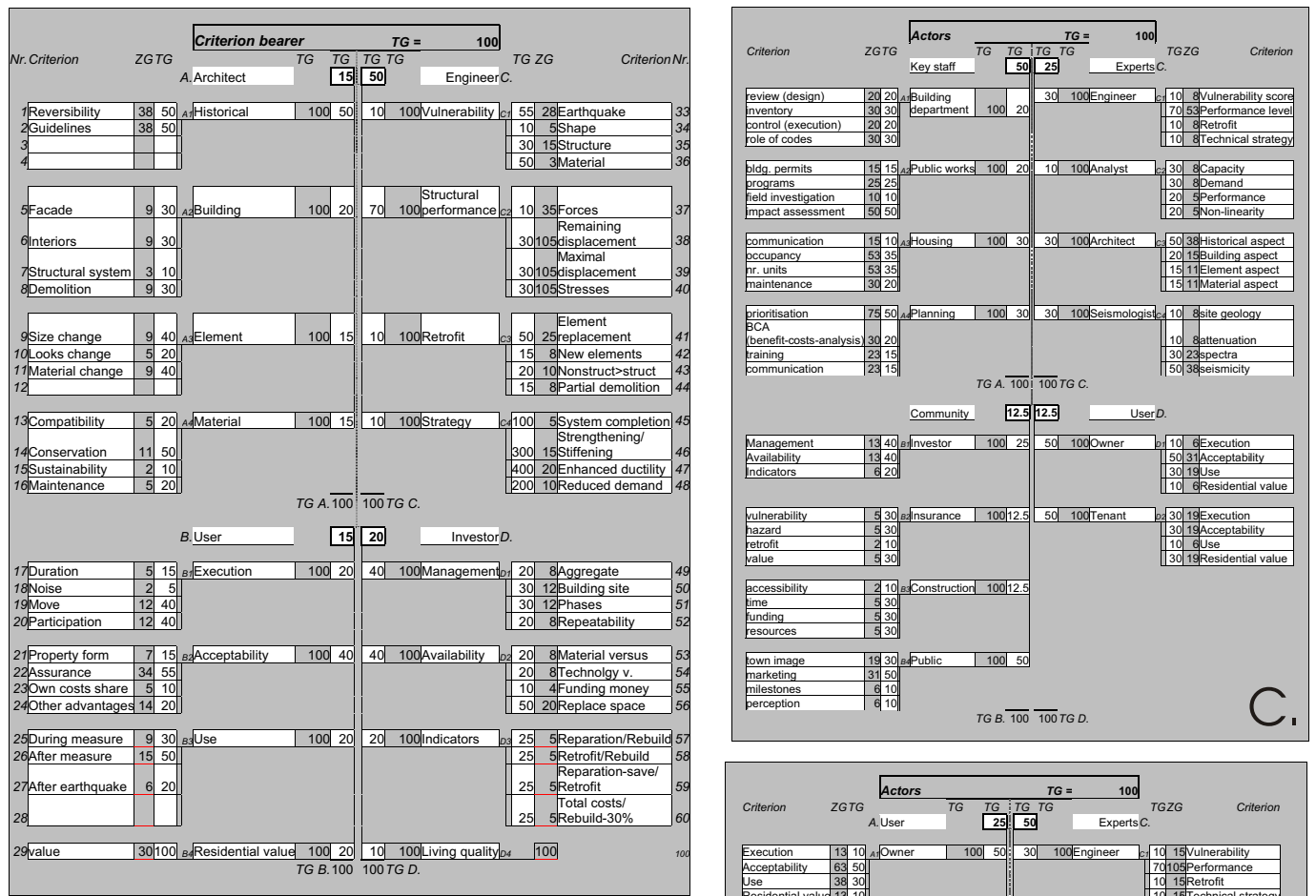

A.
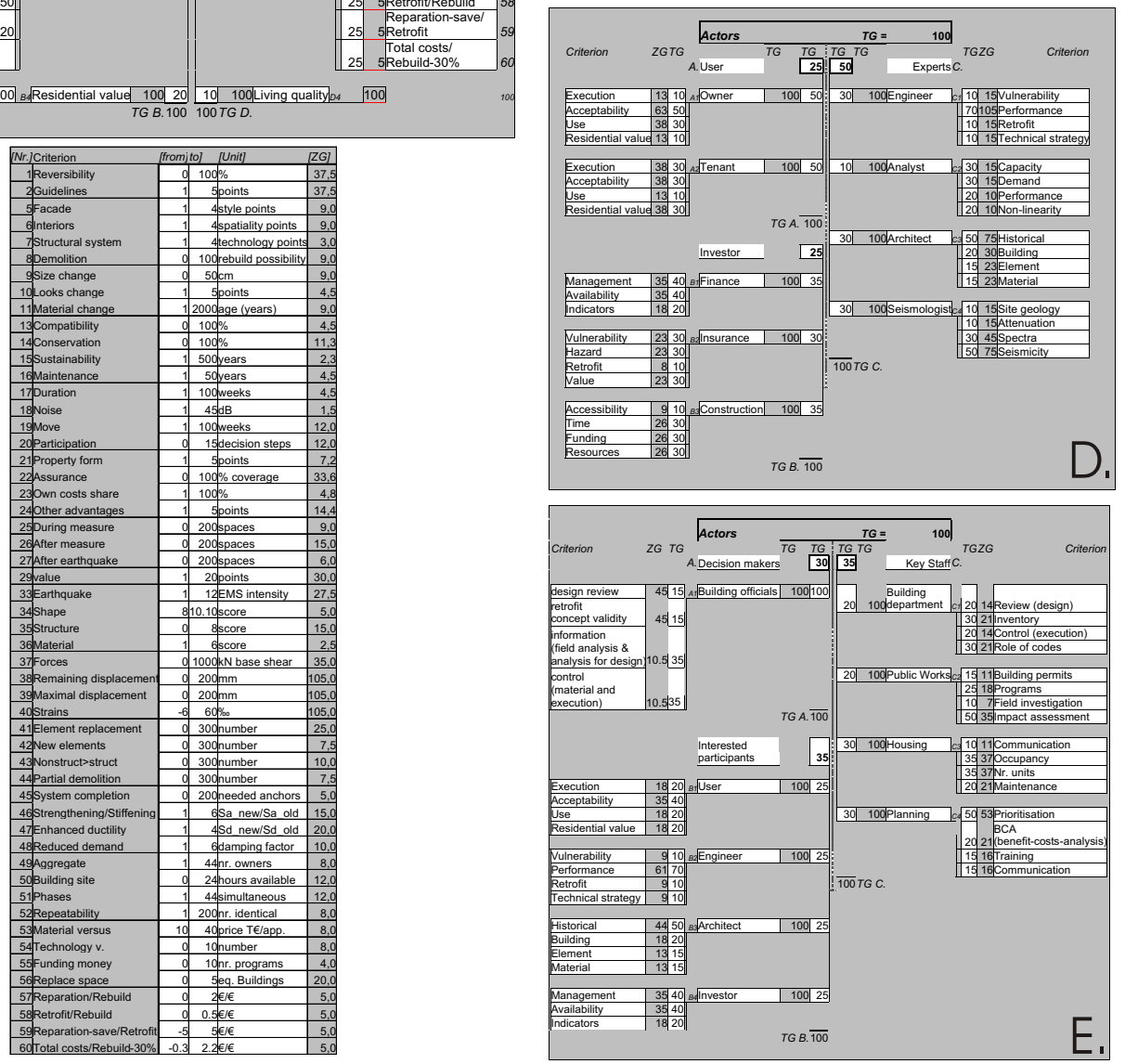

Fig. 3. Decision tree considering different actors and respectively actors' preferences to build the subdivision levels. The sum of the weights assigned to all actors together and for actors/sub-criterions respectively is each time $100 \%$. (a) Criteria of the actor categories determined in the inductive process are assigned on a 'coarse grid' and a 'fine grid'; (b) Measure space of the criteria. The criteria bearer from the decision tree in (a) are assigned each a unit of measure and a criterion value space (the columns [from] [to]). The weights for the sub-criterions are shown as well; (c) Interest groups provide for two levels in the decision tree. The same groups considered in (a), and additionally the 'key staff'; (d) Same as (b) but only considering the actors in (a), and a relevant actor was chosen for the category 'community' (corresponding to 'public'): the investor; (e) The highest level in the hierarchy, including the decision makers is considered. The actors shown at (a) are here 'interested participants' only $(\mathrm{TG}=$ relative weight, $\mathrm{ZG}=$ weight of the sub-criterion $)$. 
Table 1. Type alternatives of retrofit measures. K1 is a quantitative criterion: the strengthening costs using the respective retrofit alternative for the model building. $\mathrm{K} 2$ is also a quantitative criterion measured in the equivalent damage elements (total reparation costs for the whole building divided by the reparation costs for the highest damage in an element). K3 is a qualitative criterion ('Influence on building appearance') based on the degree influence the retrofit alternative has on flexibility in façade conformation. K4 is also a qualitative rank, meaning the extent to which activities inside the building are disturbed during the measure is applied. The retrofit alternatives considered are: addition of structural walls, steel braces and side walls respectively, as well as steel mantling and finally the status quo.

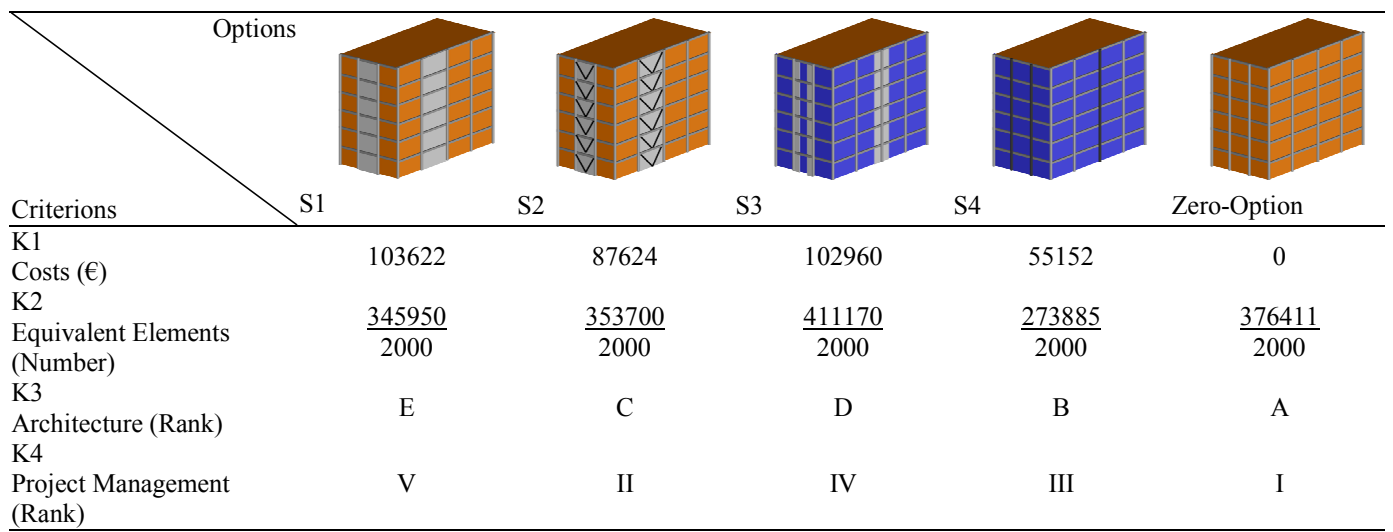

concerns which kind of 'retrofit elements' are used. The structural performance criteria set by an engineer concerns simulation results, which are flowing into the model-base, a part of the decision support system described by Malczewski (1999). The interest group 'engineer' is only interested in the technical strategies, to see which characteristics of the building are selectively enhanced through retrofit.

A reconfigured hierarchical 'goal tree' is shown in Fig. 4. The first level is represented by the problem different actors are dealing with. On the second level there are the actors themselves, treated further as criterions. The third level consists of the main criteria influencing the decision of these actors (corresponding to the "objectives" in Malczewski's work, 1999). The fourth level, contains criteria which are subdivisions of those in the level above but are measurable (corresponding to the "attributes" in the work of Malczewski, 1999). This fourth level is included in a matrix. The other dimension of the matrix features retrofit alternatives: addition of structural walls, steel braces and side walls respectively, as well as steel mantling and finally the status quo. Weights assigned as shown in Fig. 3 can be taken into consideration for each criterion in order to enable computing a score for the alternatives. For this both the outcome (fulfilment degree) of an alternative regarding a certain measurable criterion (the grey zones in the table) and the weight are taken and summed. Should the pair wise comparison method be adopted instead, the preference weights are not necessary anymore. In this case the outcomes in each column provide a ranking like that to be shown in Table 1, providing the basis for a subsequent balancing in the decision process. This way some particular criterion weighting rules can be considered: the costs-efficiency-analysis method of Richter and the "balancing principle" (Strassert, 1996). Richter's method is documented in a university intern script (Richter, P.: "Wirtschaftliche Planung". Univer- sität Karlsruhe, 1998), together with the use guidelines of a Microsoft Excel ${ }^{\circledR}$ based tool to employ that (Richter, P. and Bogenstätter U.: "Planungs- und Bauökonomie". Universität Karlsruhe, 1999), and an example individual study of the tool developer (Bogenstätter, U.: "Planungs- und Bauökonomie". Universität Karlsruhe, 1998). However, the basis for their development can be followed in more widely accessible literature (Möller, 1984; Schulte and Pierschke, 2000). Möller (1984) analyses four procedures for benefitcosts-investigation in construction:

- the benefit-costs-analysis, supposing conversion of all goals to a monetary expression before measurement;

- the utility value analysis, in which all goals are measured by means of scores;

- the costs-efficiency-analysis, where the benefit is measured by scores and the costs in a monetary way;

- the pair-wise comparison, with selection decision based on benefits and costs criterion-by-criterion comparison in qualitative cases, while weights are assigned on ordinal scale.

The decision trees in Fig. 3 include weights as defined from the costs-efficiency-analysis. Bogenstätter's computer support for the costs-efficiency method involves three steps. First, the decision tree template is filled out (Fig. 3a). Criterion measurement spaces are filled out in another template (Fig. 3b). Finally, the benefit for the respective option is assessed and the results are compiled in another table. Strassert's (1996) method can be seen as a further development of the pair-wise comparison. This is a seven step method. In a first step options and criteria are preselected. The second step serves ranking the options. In a third step 


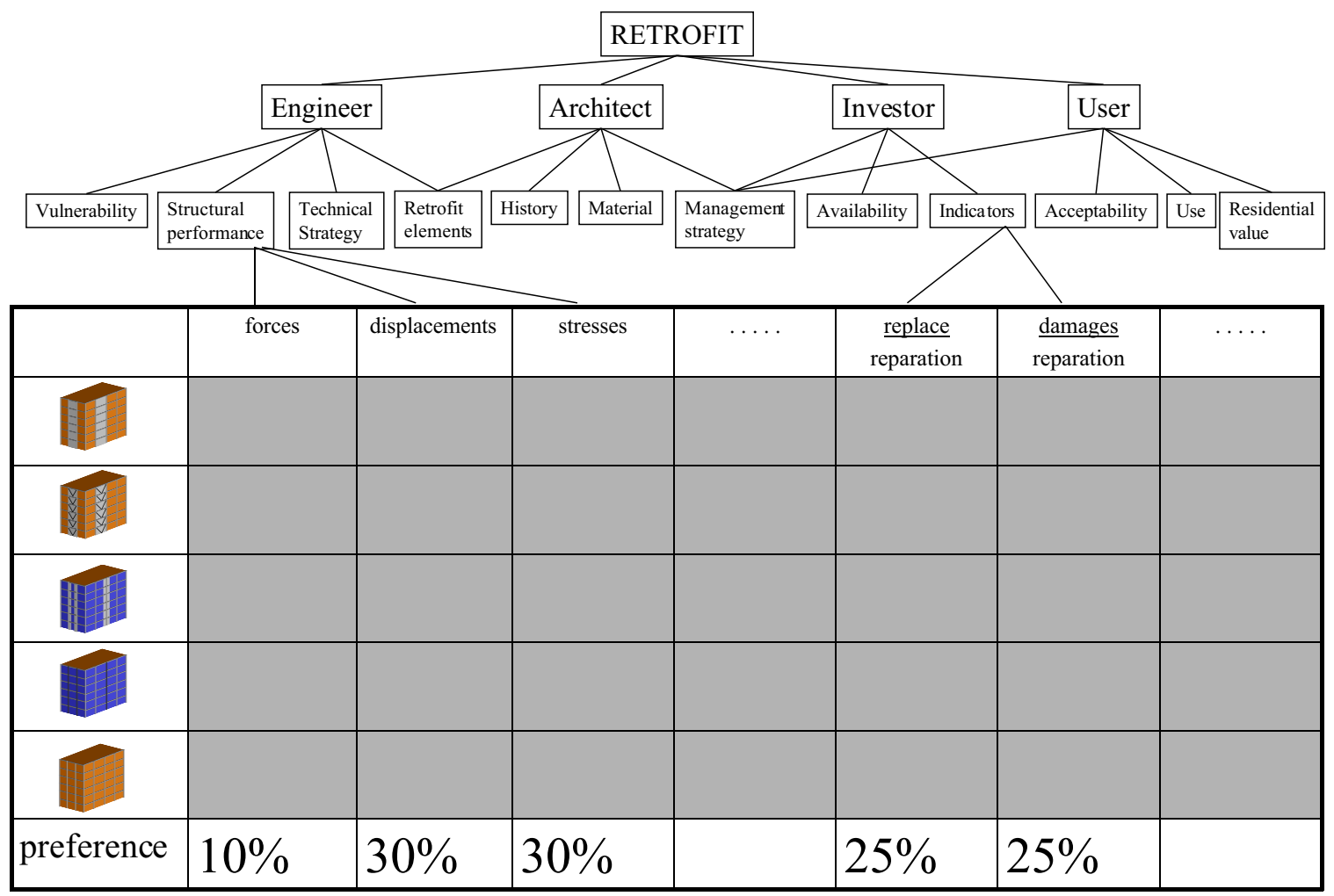

Fig. 4. Framework showing the interdependence between the goals of different decision makers, objectives and options in multi-criteria decision for retrofitting existing buildings adapted to the related skeletal structure provided by Malczewski (1999). It consists of a matrix featuring in one dimension retrofit alternatives and in the other criteria resulting from a decision tree. The hierarchy of the later includes from top to bottom in: the problem different actors are dealing with (first level), the actors themselves, (second level), main criteria influencing the decision of these actors (third level), secondary criteria (fourth level). The interior fields of the table (in grey) are to be filled with the outcome value of an alternative regarding a certain measurable (secondary) criterion. The last row contains the weights assigned to various criterions by the decision makers' preferences (as in Fig. 3).

characteristics are transformed into criteria. Decision problems start to be stated in the fourth step. In the fifth step an advantages-disadvantages table is compiled. Step 6 comprises determining the ranking space. The final step consists of a balancing loop. Balancing means in case of more actors discussion until consensus. In the technical literature (Joedicke, 1976; Möller, 1984) an instrument to facilitate discussion on actors' preferences was deemed to be promising: the transformation curve. The transformation curve shows the way score evaluation depends on the properties of the evaluated object. Thus it expresses the value structure of the actor, on which subjective preferences are based. Transformation curves for the actors' criteria determined in this paper have not been yet developed. It is to be noted that the approach in ATC-40 (1996) comes close to both rules considered: it provides for a data table for a decision matrix as required for the balancing principle of Strassert (1996) and it measures the criteria according to constraints by fixing limits like in the approach of Richter.

Table 1 includes 'what to do' action options, generated in the design phase, the same as shown in Fig. 4. Loca- tion alternatives can also generate options. K1 is a quantitative criterion meaning the strengthening costs for each retrofit alternative of the whole model building. The row including $\mathrm{K} 1$ is a ranking example from the point of view of the investor. To take into account the views of the structural engineer, dynamic analysis under different earthquake loads was run. Simulation results were obtained from stressstrain based analysis. The time history log of failure in structural elements was converted into a database of cumulative progressive damage for 'retrofit elements'. $\mathrm{K} 2$ is a quantitative criterion as well, meaning 'equivalent damage elements', computed by counting the total reparation costs for the whole building divided by the reparation costs for the highest damage in an element. Ranking as provided by K3 follows the architect's point of view. Stylistically representative buildings (Table 2) were chosen. $\mathrm{K} 3$ is a qualitative criterion meaning 'influence on building appearance'. Classes A to $\mathrm{E}$ are dictated by the degree of flexibility in façade conformation, influenced by the addition of further structural members. The Zero-Option (status quo) offers the highest flexibility, through its skeletal structure. Steel mantling represents 


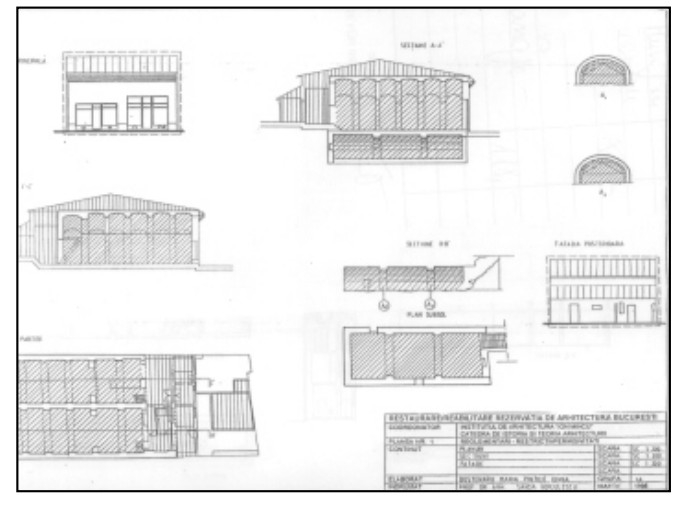

a.

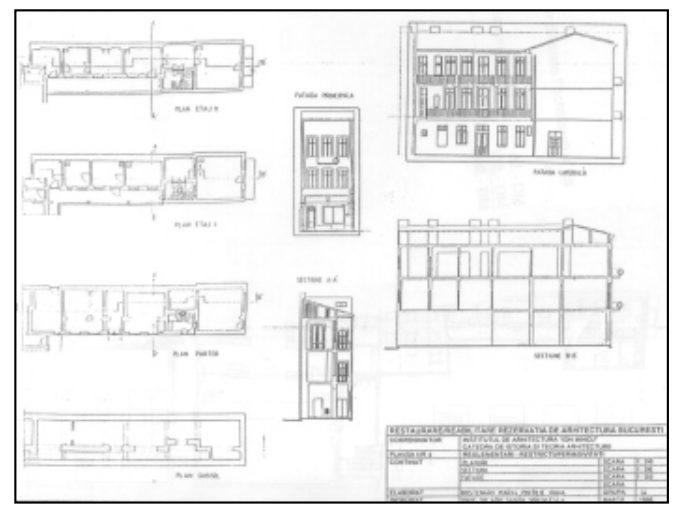

b.

Fig. 5. Problems and opportunities at building level: (a) completed survey form for a building rich in elements to be maintained (vaulted spaces); (b) completed survey form for a building with few elements to be maintained (façade and staircase only).

a minor change, through which eventually only concrete surfaces intended to remain visible are influenced. Next one in the ranking succession is the variant with steel braces, where eventual openings are still possible in the corresponding frame fields, but these are affected either in their size or look by the diagonals. Side walls influence instead clearly the size of openings in these fields and there is no range for their look. And finally the structural walls added in the whole frame offer the least flexible solution, with strong constraints concerning the possibilities for openings and retaining balconies. To take into account the inhabitant's view, the project management plans for selected measures were made, so disruption in functionality can be appraised. K4 is also a qualitative rank, meaning 'extent to which activities inside the building are disturbed during the measure is applied'. Maintaining the status quo is obviously the least disturbing measure, ranked with I. Next are ranked the measures featuring steel based retrofit elements, since these require mainly dry mounting methods. Interventions to column only like steel mantling (ranked III) or reinforced concrete side walls (ranked IV) are best performed from inside the building and thus given a higher disturbance rank. Finally embedding a structural wall within a frame is disturbing most, implying also foundation works and would require moving a looking for alternative space during the measures. The criterions included in Table 1 can be found in the decision trees started from (Fig. 3). It proves the successful regression.

The decision making methods described above use an explicit evaluation procedure. According to Joedicke (1976) such procedures are only possible, if considering more actors, in advanced project phases. Joedicke (1976) sees in this case actors being the measurement instrument. These advanced phases are the ones when construction devices are elaborated, and when 'retrofit elements' are the main structuring factor. Table 3 shows typical damages at the so called 'retrofit elements', which are building elements defined from the architectural, building survey and engineering characteristics (Bostenaru, 2003).

\section{Multi-criteria decision implementation}

The decision process is seen from a managerial point of view, emphasizing the role of the planer in this process. The 'ingredients' of a strategic plan for seismic risk reduction are action plans, objectives, operative modalities, human resources, time and costs, aiming analysis, evaluation, priority setting and communication. An urban project in existing context begins with a site analysis identifying vulnerabilities as problems and capacities as opportunities (Fig. 5). This brings the step of options in the so called "intelligence" (Malczewski, 1999) phase of the strategic decision.

An exercise on the task, to plan such a strategic intervention in a test zone was worked up in two phases (Fig. 6). The first phase serves for the recognition of problems and opportunities in the zone, by means of which a diagnosis was seized and a mission was formulated. Innovative was first of all the analysis approach. The zone wasn't uniformly assessed, but emphasing the relevant urban elements independently of scale. The method developed by Lynch in the book "The Image of the City" (Lynch, 1960) was employed. According to Lynch's theory, those who enter a town, perceive it by means of landmarks, paths, districts, nodes and edges. Exactly these elements were identified for the analysed zone (Fig. 7). The 'goal tree' was completed by identifying characteristics as problems or opportunities according to their value in regard to certain criteria. To be highlighted is the interdependency between the strengtheningopportunities/aggravating-problems (Fig. 8). If a proposed retrofit variant fulfils simultaneously some of these criteria, it can be talked of opportunities strengthening each other. If a retrofit variant fails to meet simultaneously some of these criteria, it can be talked of problems aggravating each other.

A mission for mitigation interventions is formulated in points without priorities. Each point is a sub-objective for a group of actors, meant to be reached through measures packages. Within the framework of the strategic planning also the means for reaching the envisaged goals are assigned. 
Table 2. Database query results of most vulnerable buildings from a specific type in Bucharest, Romania, namely the inter-bellum ones. Number of flats, surfaces, as wells as damages and retrofit methods following the 1977 earthquake after Lungu and Saito (2001), costs estimated with the INCERC (2000) method. Average values are highlighted (EQ = earthquake, $\mathrm{Y}=$ yes, $\mathrm{N}=\mathrm{no}, \mathrm{L}=$ low, $\mathrm{M}=$ middle, $\mathrm{E}$ $=$ extensive, $\mathrm{X}=$ some. A sum of buildings for which specific retrofit measures were applied was computed as well as a percentage for the selection of buildings in this table.).

\begin{tabular}{|c|c|c|c|c|c|c|c|c|c|c|c|c|c|c|c|c|c|c|c|c|c|c|}
\hline \multirow{2}{*}{ 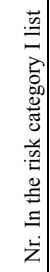 } & \multirow[b]{2}{*}{ 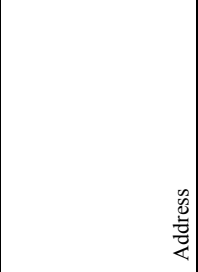 } & \multirow[b]{2}{*}{ 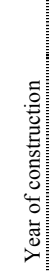 } & \multirow[b]{2}{*}{$\begin{array}{l}d \\
\stackrel{D}{D}\end{array}$} & \multirow[b]{2}{*}{$\begin{array}{l}\tilde{\omega} \\
\dot{w} \\
\tilde{d} \\
\tilde{d} \\
\approx\end{array}$} & \multirow[b]{2}{*}{ 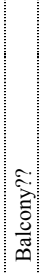 } & & \multirow[b]{2}{*}{ 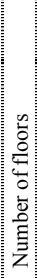 } & \multirow[b]{2}{*}{ 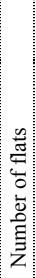 } & \multirow[b]{2}{*}{ 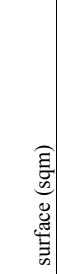 } & \multicolumn{3}{|c|}{\begin{tabular}{|c} 
damages \\
in $1977 \mathrm{EQ}$
\end{tabular}} & \multirow[b]{2}{*}{ 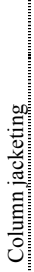 } & \multirow{2}{*}{\multicolumn{2}{|c|}{ 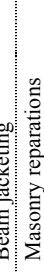 }} & \multirow[b]{2}{*}{ 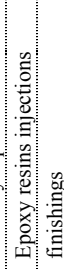 } & \multirow[b]{2}{*}{ 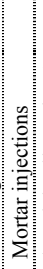 } & \multirow{2}{*}{ 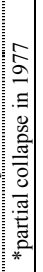 } & \multirow[b]{2}{*}{ 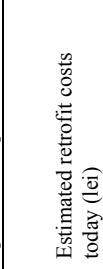 } & \multirow[b]{2}{*}{ 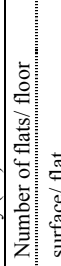 } & \multirow{2}{*}{$\begin{array}{l}2 \\
0 \\
0 \\
0 \\
\frac{\pi}{4} \\
0 \\
0 \\
0 \\
0\end{array}$} & \multirow{2}{*}{ 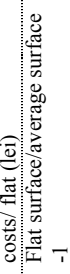 } \\
\hline & & & & & & & & & & 咅 & 胥 & 资 & & & & & & & & & & \\
\hline & Maria Rosetti 55 & 1934 & 4 residential & $\bar{Y}$ & $\mathrm{Y}$ & $\mathrm{N}$ & 9 & 20 & 2209 & $\mathrm{~L}$ & $\mathrm{~L}$ & $\mathrm{E}$ & & & $\mathrm{X}$ & & $\mathrm{X}$ & & 5.913 .493 & 2110 & 0295.675 & $75-0,20$ \\
\hline 11 & Magheru 27 & 1935 & 5 residential & 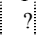 & ? & $\mathrm{Y}$ & 9 & 36 & 6405 & $\mathrm{~L}$ & L & W & $X$ & & & & & & 17.146 .185 & 4177 & 7776.283 & $33: 0,27$ \\
\hline 16 & 6) Calea Victoriei 128A & 1935 & 5 residential, commercial & $\mathrm{Y}$ & $\mathrm{Y}$ & $\mathrm{Y}$ & 9 & 22 & 6675 & & E & E & $\mathrm{XI}$ & $X$ & $X-$ & & $\bar{z}$ & & 17.868 .975 & 2,5303 & 3812.226 & 261,178 \\
\hline & Ştirbei Vodă 17 & 1936 & 6 residential, commercial & $Y$ & $\mathrm{Y}$ & $\mathrm{Y}$ & 9 & 58 & 6140 & & $\mathrm{M}$ & 党 & & & $x$ & & & & 16.436 .780 & 6,5105 & 5 & $3-0,23$ \\
\hline & 7 Calea Victoriei 208 & 1940 & 0 residential & $?$ & $?$ & $\mathrm{Y}$ & 8 & 44 & 5200 & & $\mathrm{M}$ & $\mathrm{E}$ & & $\mathrm{X}$ & $X$ & $X$ & & & 13.920 .400 & 5118 & 816.373 & $73-0,15$ \\
\hline & Poenaru Bordea 16 & 1936 & 6 Iresidential & ?ר: & ? & $\mathrm{N}$ & 8 & 30 & 3100 & & $\mathrm{~L}$ & & & & & & & & 8.298 .700 & 4103 & 33276.623 & $23-0,25$ \\
\hline & 3 Lahovary $5 \mathrm{~A}$ & 1935 & 5 residential, office & $\mathrm{Y}$ & $\mathrm{Y}$ & $\mathrm{Y}$ & 8 & 18 & 2955 & & $\mathrm{E}$ & $\mathrm{E}$ & $\mathrm{X}$ & $\Lambda$ & & & X- & & 7.910 .535 & 2164 & 44.439 .474 & 740,17 \\
\hline & Nicolae Iorga 22 & 1939 & 9 Sresidential & $\mathbf{Y}$ & $\mathbf{Y}$ & $\mathrm{N}$ & 7 & 31 & 3140 & & $\mathrm{~L}$ & $E$ & $\mathbf{X}$ & $\mathbf{X}$ & $\mathbf{X}$ & & & & 8.405 .780 & 4101 & 1271.15 & $-0,27$ \\
\hline & Pitar Moş 29 & 1936 & oresidential & & 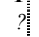 & $N$ & 7 & 59 & 4639 & & $E$ & & $X$ & $X$ & & & & & 12.418 .603 & & 8210.485 & $5-0,43$ \\
\hline & $\begin{array}{l}\text { Stelea Spătarul } 17 \\
\text { Bălcescu } 25\end{array}$ & 1937 & $\begin{array}{l}7 \text { residential } \\
\text { residential, }\end{array}$ & $Y$ & $\mathrm{Y}$ & $\mathrm{N}$ & 7 & 53 & 4125 & & $\mathrm{E}$ & $\mathrm{M}$ & $X$ & $x$ & 1 & & & & 11.042 .625 & 87 & 7208.351 & $1-0,44$ \\
\hline 61 & (Wilson) & 1928 & 8 office, commercial & $\mathrm{Y}$ & $\mathrm{Y}$ & $\mathrm{Y}$ & 12 & 93 & 12287 & & $\mathrm{E}$ & $\mathrm{E}$ & $\mathrm{X}$ & $x$ & $\mathrm{x} x$ & $\mathrm{X} X$ & $\mathrm{X}$ & & 32.892 .299 & 8132 & 2353.681 & $1-0,05$ \\
\hline & Calea Victoriei 25 & 1936 & 6 residential, commercial & $Y$ & $\mathrm{~N}$ & $\mathrm{Y}$ & 13 & 49 & 6078 & & $\mathrm{E}$ & $\mathrm{E}$ & $\mathrm{X})$ & & & $X-$ & & & 16.270 .806 & 4124 & 4332.057 & $7-0,10$ \\
\hline 93 & Nicolae Golescu 5 & 1938 & 8 residential, commercial & $Y$ & $\mathrm{Y}$ & $\mathrm{Y}$ & 10 & 21 & 1766 & & $\mathrm{~L} / \mathrm{\Lambda}$ & & & & & & & & 4.727 .582 & 284 & 2425.123 & $3-0,39$ \\
\hline 96 & Mihai Eminescu 17 & 1937 & 7 residential, commercial & $\mathbf{N}$ & $\mathbf{N}$ & $\mathbf{Y}$ & 8 & 40 & 6063 & & L & L & & & $X=$ & & & & 16.230 .651 & 5151 & 41405.766 & 60,08 \\
\hline 100 & Nicolae Bălcescu 7 & 1933 & 3 residential, commercial & $\mathrm{Y}$ & $\mathrm{Y}$ & $\mathrm{Y}$ & 7 & 15 & 2730 & $\mathrm{~L}$ & L & E & & & $X$ & $X$ & & & 7.308 .210 & 2182 & 2487.214 & 40,30 \\
\hline 102 & Luchian 3 & 1936 & 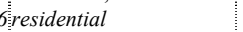 & $Y$ & $Y^{3}$ & $N$ & 6 & 9 & 2067 & $M / E$ & - & E & $X$ & & $X-$ & & & & 5.533 .350 & 1,5229 & 每 & 0,64 \\
\hline & Calea Victoriei 33-35 & 1930 & osidesidential, commercial & ? & $?$ & $\mathrm{Y}$ & & 39 & 4800 & & $\mathrm{M}$ & $\mathrm{M}$ & $\mathrm{X}$ & & $X-$ & & & & 12.849 .600 & 6123 & 3329.477 & $7-0,11$ \\
\hline & $\begin{array}{l}\text { MEAN VALUE } \\
\text { Min } \\
\text { Max }\end{array}$ & & & & & & \begin{tabular}{r|}
9 \\
6 \\
13
\end{tabular} & $\begin{array}{r}37 \\
9 \\
93\end{array}$ & \begin{tabular}{r|}
4728 \\
1766 \\
12287 \\
\end{tabular} & & & & & & & & & & & \begin{tabular}{|r|r|}
4 & 139 \\
1,5 & 77 \\
8 & 303 \\
\end{tabular} & \begin{tabular}{|l|l|}
9 & 372.834 \\
7 & 208.351 \\
3 & 812.226
\end{tabular} & \\
\hline & $\begin{array}{l}\text { Sum } \\
\%\end{array}$ & & & & & & & & & & & & $\begin{array}{l}9 \\
8\end{array}$ & $\begin{array}{l}6 \\
5\end{array}$ & & $\begin{array}{lr}6 & 1 \\
5 & 0,9\end{array}$ & $\begin{array}{l}3 \\
20\end{array}$ & $\begin{array}{r}1 \\
0,9\end{array}$ & & & & \\
\hline
\end{tabular}

A measures package includes: consensus (communication) means, implementation means and finally implementation plans at different levels and time horizons, taking form in action plans. Implementation means result in model and pilot projects for operations, which are also concretisation forms for action plans. As the result of the implementation has to be evaluated from time to time, the planning aim is not a product but an action and learning process for all implied actors (see the diagram of learning process in Bostenaru, 2004). Thus time and human resources cannot be assigned to each objective like the operative modalities were.

For the impact assessment, lacking another measuring possibilities, the classical regulation instruments could be taken: the indicators. The future development can be visualised, after the collection of the respective data, through scenarios, visions and simulations. Another unit of measure, different of indicators of all kind, is needed therefore, called here 'seismic print'. The print measures the impact of an earthquake using a surface as an urban unit. In case of an earthquake each code defines the building categories which have to remain fully operational. Thus an aggregate structure results representing the load-bearing capacity requested by the antiseismic intervention strategy from the urban system. An operation plan does not concern the zone, which is object of the study, only, but also the flows which connect it to another zones (Fig. 9). An operation plan can become in this case a model project. It can be a demonstration of rehabilitation for upgrading seismic performance. The strategy must contain stimulation to participation and public sense of responsibility. It counts on supporting the politic and administrative decisions for a new environment through a new behaviour of the people. A comprehensive scheme illustrating similar objectives to be followed and the actors to be involved in various phases of seismic risk appropriation is shown in RISKUE (2004). Information is important to build public ideas (as shown in the GrünGürtel project, Frankfurt, Germany; see Koenigs, 1991). These open up ways for the strategy implementation. The participation is a feedback element in the urban planning operation. In this way the problems opened up by the new development are reduced to the scale of the citizen. Participation asserts in the first instance the problems coupled to the habitat, on the level of quality of life.

The scheme in Fig. 9 highlights the possible zoom between layers at different scales and the concerns of three categories of actors at each of these. The subdivision into main layers like 'zone', 'building' and 'element' allows for the integration of information coming from so many different backgrounds. At each level the focus is on proprietary problem statements, but communication with those bellow and above is allowed over zooming interfaces. On the right side the placement of the stages, for which specific approaches were developed, in the intermediary space between levels of 


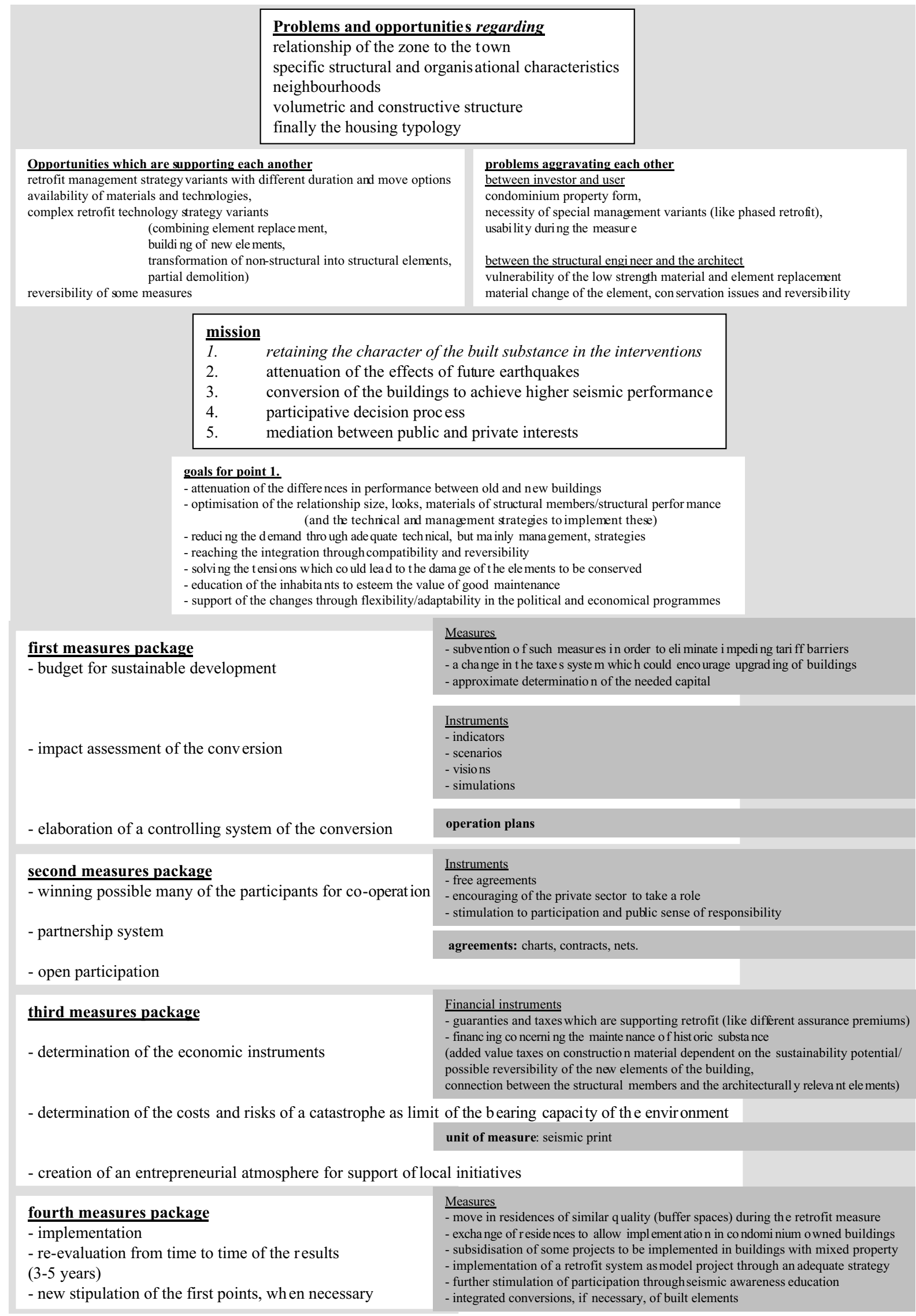

Fig. 6. Some 'ingredients' of an urban strategic plan for seismic retrofit. From top to bottom: problems/opportunities, diagnosis, mission, measures packages with implementation means. 
Table 3. Retrofit elements in the judgemental phase showing typical damages (after Bostenaru, 2003). RC = reinforced concrete, URM = unreinforced masonry, 3D = three dimensional, 'cellular' and 'fagure' are the local names for two typical Romanian construction techniques.

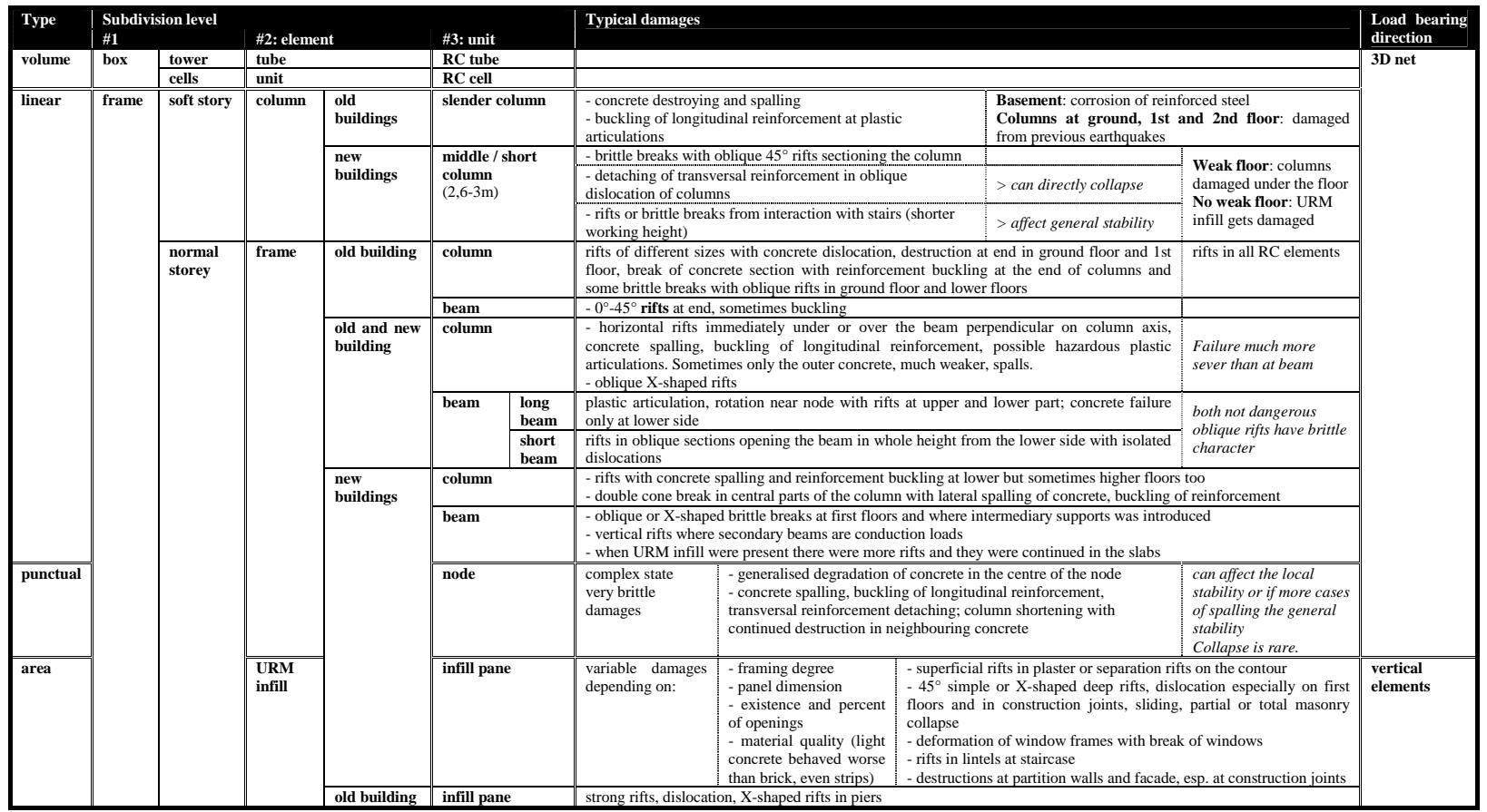

action can be seen. Setting risk evaluation criteria is based on data collection on urban scale and setting building priorities on building scale, implying hazard, vulnerability and capacity appraisal of the inventory. It is a step between problem definition and criterion weighting in the "intelligence" (Malczewski, 1999) phase. The choice takes place in the decision space between setting priorities on building scale and issuing the recommendation. Priorities are set according to decision rules agreed by the actors based on the 'goal tree' (Fig. 8) taken into consideration as shown in Fig. 1. The recommendation for a certain building retrofit system is put forward on detailed building element scale. The main constraints are the goals, the instruments, the benefits and the costs. The last step in the decision process is the efficiency evaluation. After agreeing about the retrofit system a retrofit strategy of that has to be designed. This 'implementability' evaluation calls for an impact study spanning between quality improvement, legal frame, potential acceptance and level of action as constraints and aiming at choosing a site for implementation, a corresponding implementation program and adequate resources. On the left side categories of actors and their ways of acting when dealing with the problem 'retrofit of existing buildings' can be seen at the same three levels sketched in the zooming diagram on the right side. An "image" can be marketed to the wide public. This means on urban level setting landmarks (Lynch, 1960). On building level there are more specific views and the accent in marketing actions moves towards the silhouette and the interaction of a certain building with the built context. On the level of a building element related differences are given by texture and building material.
There are more and more perception details. The operations concerning the application of a construction measure have to be managed. This is an experts' task and is made differently at various scales. Urban plans are part of the management strategy, they act as integrating vision. On building level the planning, with more details than in the layer above, is concerned with project management tasks. Building elements are the object of expert simulations for the technical strategy managing a retrofit solution. The participation of active affected people is a process and has to be treated accordingly. On the large urban scale there is no hierarchy of the actors, only a network in order to build the "image" (Lynch, 1960) of the site. Closer, on the building layer, there is place for talks between the participants, for example in a neighbourhood forum. Details can even request for a workgroup in special workshops.

Problem based orientation, differentiation of the actors as well as identification and activation of target groups lead to education, which accentuates personal implication and action motivation. Within the strategic planning classical plans and traditional organisation structures are not anymore outgoing or endpoint of the planning procedure, but elements in a dynamic process. The plan, which can exercise its power through its integrating vision, is part of the strategy (Fig. 7).

\section{Discussion}

The application to the problem of building retrofit can be cast into the generic framework for multi-criteria decision analysis. The data examination means identifying the problems, 
Table 3. Continued.

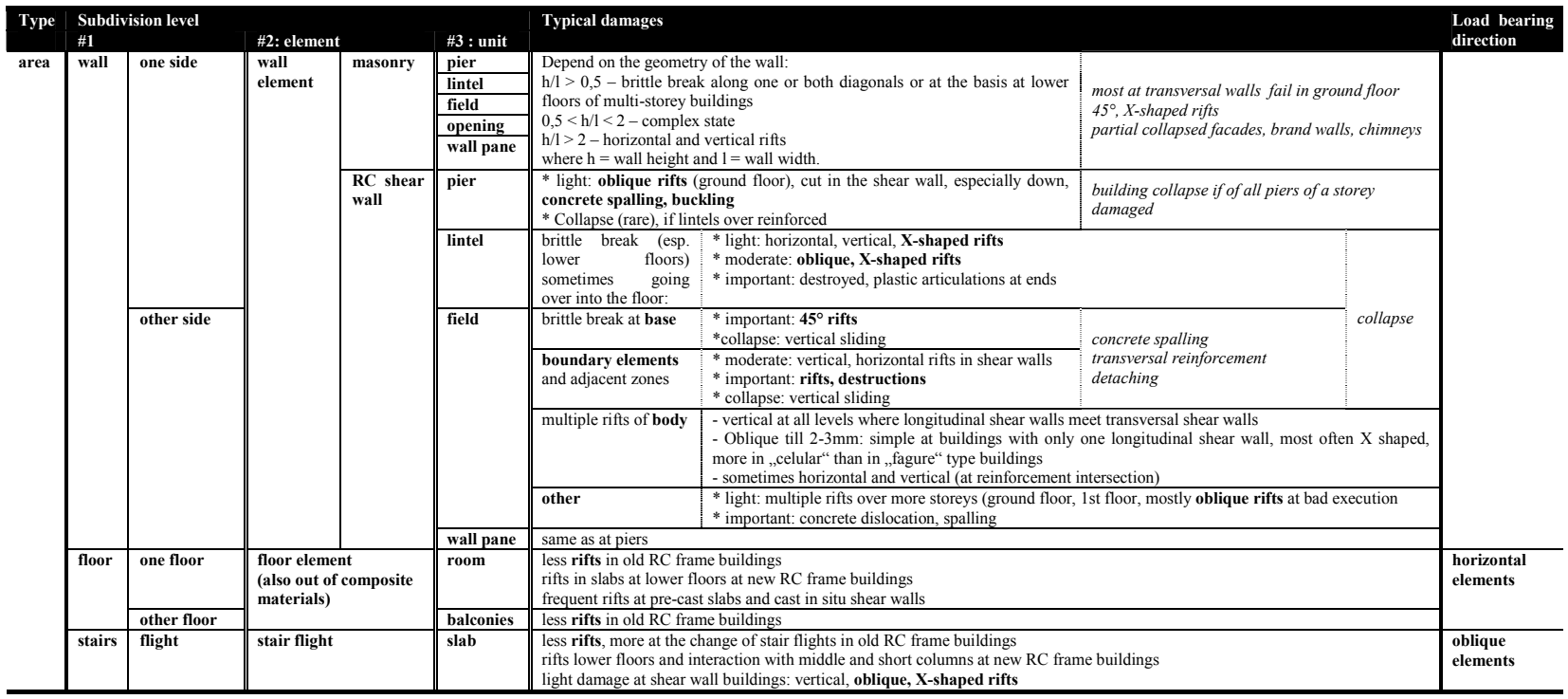

ex. insufficient resistance, and opportunities, ex. places for structural walls, and elaborating a decision tree by the regressive method. The decision model aims to facilitate collaboration between these actors.

A systematic approach, which supposes subdivision and thus instruments from project management, like the structure plan, is adequate. It allows for taking into account the information need of different actors and making a structure considering elements needed by all: visual-recognition/elements/local-retrofit-measures. Buildings have been modelled following the criteria of spatial decision support systems into spatial elements ('retrofit elements') which are characteristic for the survey, present typical damages in case of an earthquake and are decisive for a better seismic behaviour in case of retrofitting. This includes identifying the corresponding spatial elements of buildings, according to the information needs of actors from different spheres like architects, construction engineers and economists. A systematic approach cannot replace the concept, but only verify the solution by comparing it to others (Joedicke, 1976). Therefore, using such an approach is suitable from the step of decision on, as employed here, and not in earlier planning phases. But a systematic approach builds a very good basis for discussion and argumentation, as in multi-criteria and multi-actor decisions, and contributes thus to a good communication in the risk-management process. Since the degrees of participation achieved along time shall be seen as levels, not phases (Bostenaru, 2004), the strategic planning system proposed can be cast into a frame featuring various participative approaches at relevant levels in deciding about building retrofit: urban, zonal and building levels.

The interests of four different actors or actor categories can be taken into account in the environment supported by Richter for the costs-efficiency method. These were derived by regression. However, this way important categories like 'building officials', or 'seismologist' are not taken into account. The limitation on the number of actors and criteria is a deficit of the environment, but the efficiency view overcomes a difficulty, existing in related approaches, to find similar units of measure for each criterion. An alternative to consider more actors while decreasing the number of levels on which criteria are deducted was investigated as well. Richter's costs-efficiency-analysis method was developed to support choice among options in planning new buildings. Strassert's (1996) method was developed to respond to problems in regional planning. In case of the "balancing method" (Strassert, 1996) a limitation through the size of the problem occurred, too. Although computer support was developed for this method, this has not been available to the author. A great flexibility is provided with this method in measuring possibilities of the criteria, various scales being allowed and the values being taken as-it-is into the subsequent steps. But the number of criteria contained in the decision tree was overwhelming compared to the possibilities of the method. Therefore interactivity between the decision makers and computer, as investigated by Malczewski (1999) is recommended for the successful application. Advantages of programming the decision support in multimedia include the possibility of combining factual data with visual data and the possibility to adjust to a variable number of criteria and situations. A problem encountered when choosing the decision rule was a scale one: if the buildings to be retrofitted should be selected from a certain type or from a certain zone. The possibility to make the choice typologically and not zonebased was investigated. While pure regional planning supported decision works with urban areas as entities, this approach allows working with groups of buildings of similar types spread in different areas. Computer support can 


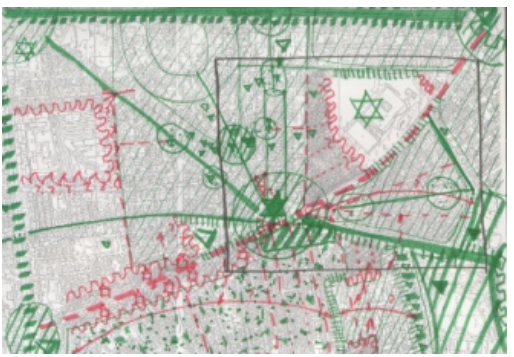

a.

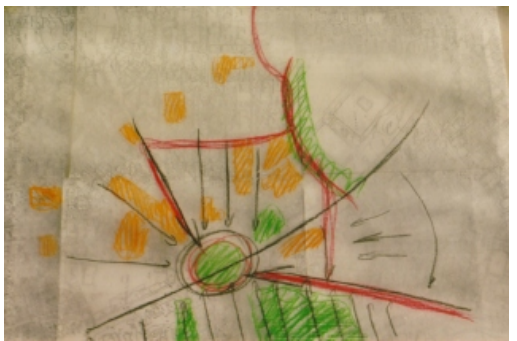

d.

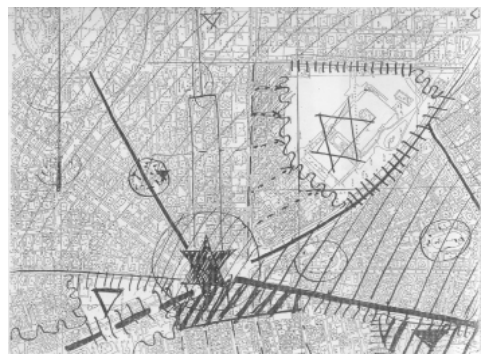

b.

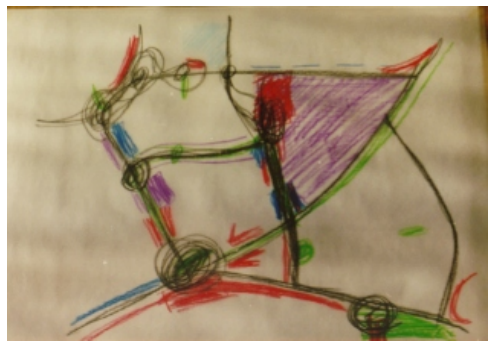

e.

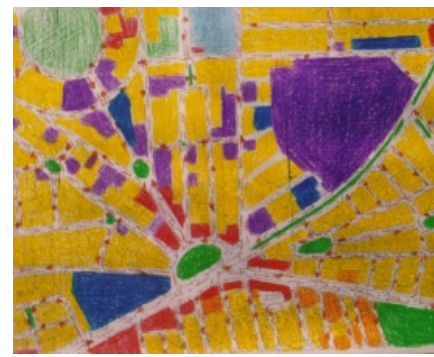

C.

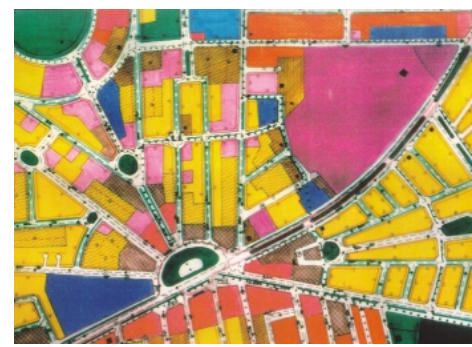

f.

Fig. 7. Steps in strategical planning for an urban zone: 1) Assigning problems (red) and opportunities (green) for the larger urban zone (a); 2) Concentrating on the potentials (opportunities only) of the closer zone, from the point of view of perception (b); 3) Performing a classic urban study for the zone (c). There is no integrating concept; 4) Highlighting potentials through the filter of urban zonification (d); 5) Vision of a future development (e); 6) Regulatory urban plan of the future development (f) integrating the vision (e) besides site analysis (c). Symbols as described in Lynch (1960) in (a) and (b); colours symbols in (d) and (e) for: valuable building stock (orange), streets with character (black), zone boundaries (red), landmarks (blue), vegetation (green), special buildings (magenta); zone rendering in (c) and (f): housing (yellow), educational (dark blue), sanitary (light blue), commercial (red), mixed (orange), recreation (green), and special (magenta).

appropriately take into account such a type of options. For this purpose an adaptation of the "Pattern language" (Alexander et al., 1977) principle to the type of data in the World Housing Encyclopedia (EERI, 2004) is suitable. The building typologies considered in impact assessment are the same ones over which reports for the Encyclopedia are compiled. Decision support shall rely in this case on the possibilities of hypertext and internet. An expert system is thus transformed into a multi criteria decision model.

\section{Conclusions}

Developing a decentralised decision model, encompassing all actors involved in the implementation strategy of a retrofit measure, from different backgrounds: geophysics/engineering seismology, (structural) engineering, architecture, economy (investment efficiency) and sociology (consideration of user issues) is an objective for which interdisciplinary aspects are of importance. Seeking for ways of solving contradictions between the objectives of single actors in the retrofit implementation strategy, not only through choice, but also through the customisation of an adequate decision system implies multidisciplinary aspects. The comprehensibility of the retrofit measures is highlighted through inclusion into an integral planning scheme near the flow in the physical implementation of the retrofit system also of a flow for the education of the population which has to support the measures (Bostenaru, 2004). This is especially important in the so-called second phase of strategic implementation, when the application of the measure has to spread from pilot or demonstrative projects to "routine" wide ones. Integral planning means here the development of a framework in which conformation, engineering and economic aspects are equally regarded from incipient phases of reconversion projects. The nature of the problem stated needs a decision model based on which actors involved in the implementation of a retrofit measure can interact. In this paper it was also presented how to implement such decisions in a strategic way. Different levels of intervention and different instruments used for strategic planning respond to the needs of actors from several categories, which participate in the decision process. The decision doesn't take place anymore on one stage, before implementation, but accompanies it, thus becoming the model of a decision process.

Acknowledgements. The author thank to the guest editor T. Glade for the opportunity to publish in this issue and for the editorial assistance in preparing this paper. Thanks go also to the referees for assisting in evaluating this paper and for the very helpful comments in improving its quality.

The financial support of the German Research Foundation (DFG) for the entire doctorate research as well as the research term funded by the European Commission within this research are gratefully acknowledged. Section 3 in this paper is part of that research. Special thanks go to one of the co-referents of the doctorate work, Prof. Richter at the Universität Karlsruhe (TH), whose 


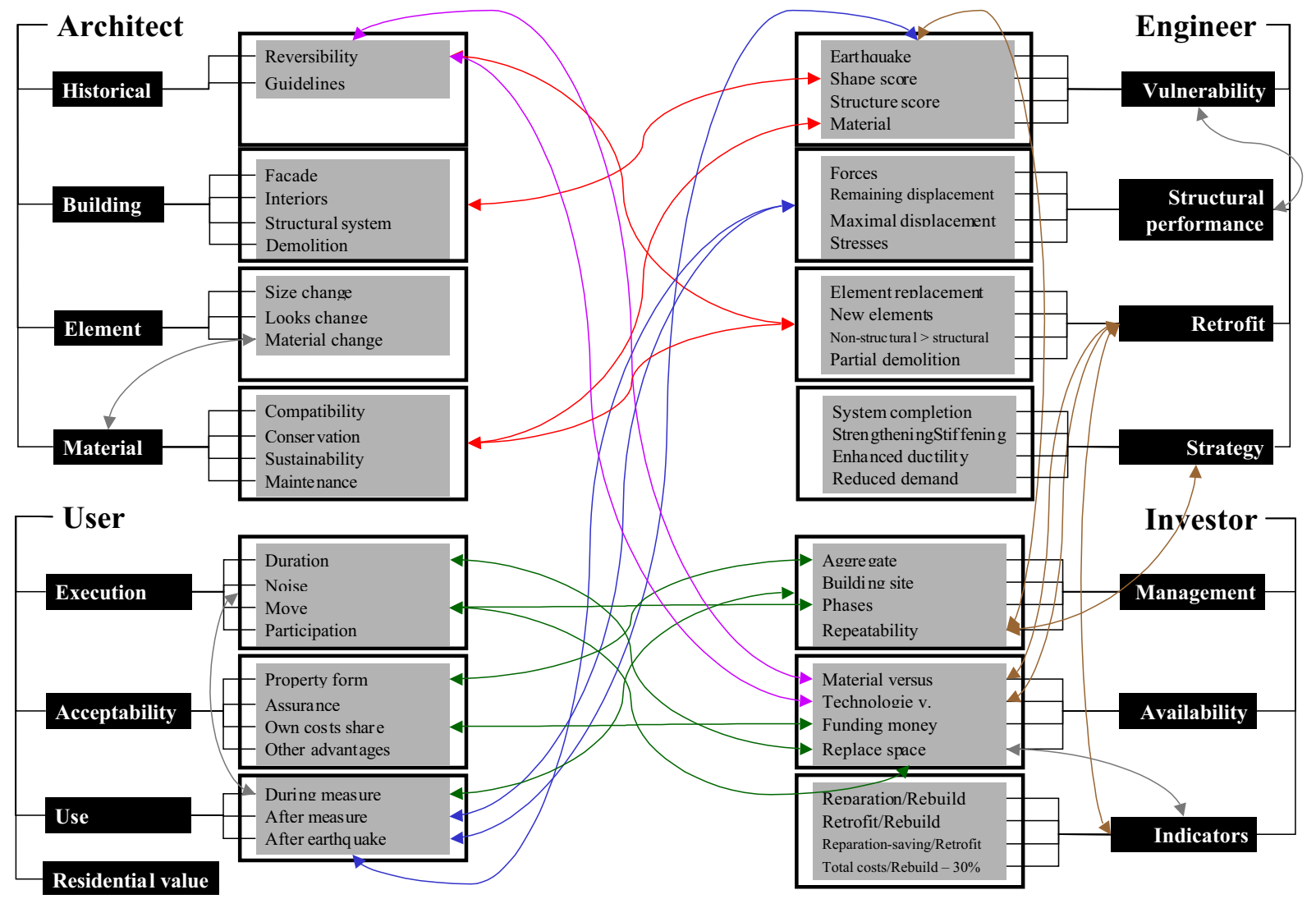

Fig. 8. Problems and opportunities aggravating/strengthening each other between criteria set by different or the same decision maker (marked by coloured arrows). The criteria are structured in a goal tree, and weights are assigned on both 'coarse' and 'fine' criterion grids (a grid levels hierarchy was shown in Fig. 4). From top to bottom the hierarchy of criteria corresponds for each actor to different levels of investigation (as it will be visualised in Fig. 9).

costs-efficiency-analysis models were employed in this research (see http://www.poeb.uni-karlsruhe.de/ for contact details from where documentation could be obtained).

\section{Edited by: T. Glade}

Reviewed by: two referees

\section{References}

Alexander, Ch., Ishikawa, S., and Silverstein, M.: A Pattern Language. Towns. Buildings. Construction, Oxford University Press, New York, 1977.

ATC-40: Seismic Evaluation and retrofit of concrete buildings, CSSC, California, 1996.

Bostenaru Dan, M.: Wirtschaftlichkeit und Umsetzbarkeit von Gebäudeverstärkungsmaßnahmen zur Erdbebenertüchtigung = Applicability and Economic Efficiency of Seismic Retrofit Measures on Existing Buildings (in German), edited by: Tetzlaff, G., Trautmann, T., and Radtke, K.S., Second Forum on Catastrophy Mitigation, 128-135, DKKV, Bonn/Leipzig, and www.dkkv.org/ forum/Datei17.pdf, 2002.

Bostenaru Dan, M: Interpreting the photographical information stored in multimedia GIS, GK450, University of Karlsruhe, 2003.

Bostenaru Dan, M.: Review of retrofit strategies decision system in historic perspective, Nat. Haz. Earth Sys. Sci., 4, 3, 449-462, 2004.
Comartin, C. D., Niewiarowski, R. W., Freeman, S. A., and Turner, F. M.: Seismic Evaluation and Retrofit of Concrete Buildings: A Practical Overview of the ATC 40 Document, Earthquake Spectra, 16, 1, 241-261, 2000.

EERI (Earthquake Engineering Research Institute): World Housing Encyclopedia, www.world-housing.net, 2004.

FEMA 154: Rapid Visual Screening of Buildings for Potential Seismic Hazards: A Handbook, FEMA, Washington, D.C., 1988.

Fingerhuth, K. and Koch, M.: Gestaltung zwischen Entwurf und Vereinbarung. Zur Verständigung über Funktion und Ästhetik bei der Planung und Realisierung von Neubauten = Conformation betwen Project and Agreement. On the Understanding of Function and Aesthetics in the Planning and Realisation of Buildings (in German), edited by Selle, K., Planung und Kommunikation = Planning and Communication (in German), Bauverlag, Wiesbaden, 23-40, 1996.

Habraken, N. J.: SAR Design Method for Housing: Seven Years of Development in the Real World, DMG-DRS Journal for Design Research Methods, 7, 3, 1973.

Hempel, H. and Uhl, O.: Kooperatives Planungshandeln, partizipatorisches Bauen in einer prozessualen Architektur = Co-operative Planning Action, Participative Construction in a Processual Architecture (in German), Bauforum, 15, 90, 8-16, 1982.

IBA: Die Internationale Bauausstellung Emscher Park (1989_ 1999) $=$ The International Construction Exhibition Emscher Park (1989-1999) (in German), www.iba.nrw.de, 1999. 


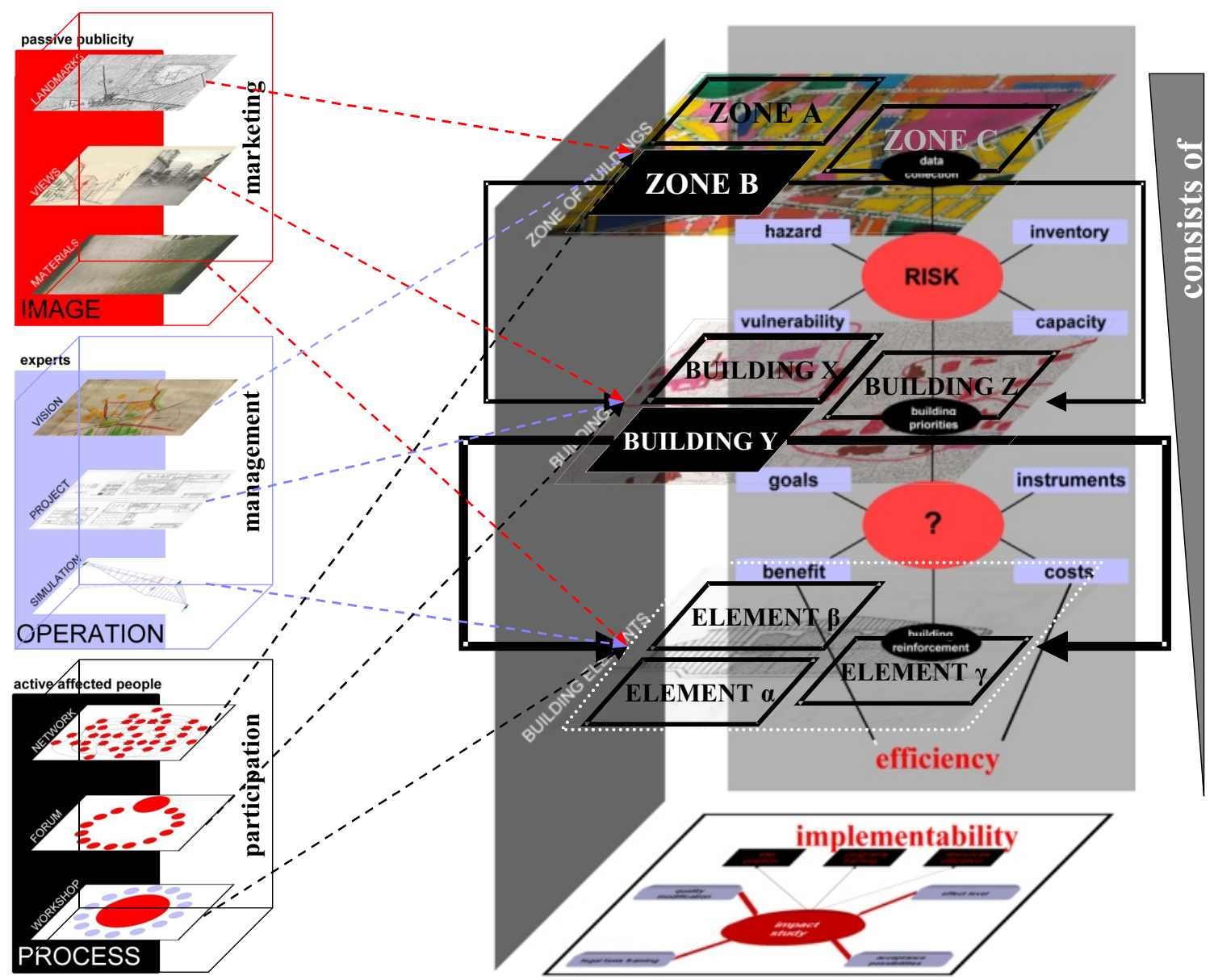

Fig. 9. Relationship between planning layers and actors in the multi-criteria decision process in retrofitting existing buildings. This scheme highlights the possible zoom between layers at different scales ('zone', 'building', 'element'). On the left side categories of acting can be seen: the passive publicity addressed by marketing the "image", experts responsible for management operations and affected people active in participation processes. On the right side specific approaches developed the intermediary space between levels of action can be seen: risk assessment (between urban and building scale) and the choice, marked by a question sign (between building and building element scale). All layers superposed decide about the 'implementability' (bottom right), spanning between constrains (on grey) and aiming at certain budgets.

INCERC: Probleme de economia construciilor = Construction Economy Problems (in Romanian), 3, 2000.

Joedicke, J.: Angewandte Entwurfsmethodik für Architekten = Applied Design Methodology for Architects (in German), Karl Krämer, Stuttgart, 1976.

Koenigs, T. (Ed.): Vision offener Grünräume: Grüngürtel Frankfurt $=$ Vision on Open Green Spaces: GreenBelt Frankfurt (in German), Campus-Verl., Frankfurt/Main, 1991.

Lungu, D. and Saito, T. (Eds.): Earthquake Hazard and Countermeasures for Existing Fragile Buildings, Independent Film, Bucharest, 2001.

Lynch, K.: The Image of the City, MIT Press, Cambridge MA, 2000 (27th edition; first edition 1960).

Malczewski, J.: GIS and Multicriteria Decision Analysis. John Wiley \& Sons, New York, 1999.

Möller, D.-A.: Planungs- und Bauökonomie = Design and Construction Economics (in German), Volume 1, Oldenbourg, München, 2001 (fourth edition; first edition 1984).

Mouroux, P., Bertrand, E., Bour, M., Le Brun B., Depinois S., Mauser P., and the RISK-UE Team: The European RISK-UE
Project: An Advanced Approach to Earthquake Risk Scenarios. Proceedings of the 13th World Conference on Earthquake Engineering, Vancouver, B.C., Canada, 1-6 August, Paper No. 3329, 2004.

Nägele, H.: Die Restaurierung der Weißenhofsiedlung 1981-1987 = The Restoration of the Weißenhof Siedlung 1981-1987 (in German), Karl Krämer, Stuttgart, 1992.

RISK-UE: An advanced approach to earthquake risks scenarios, with application to different European towns, Synthesis of the application to Nice city, ftp://ftp.brgm.fr, 2004.

Saaty, T. L.: The analytic hierarcy process. McGraw-Hill, New York, 1980.

Schulte, K.-W. and Pierschke, B. (Eds.): Facilities Management (in German), Part D, Rudolf Müller, Köln, 368-404, 2000.

Strassert, G.: Das Abwägung bei multikriteriellen Entscheidungen, Grundlagen und Lösungsansatz - unter besonderer Berücksichtigung der Regionalplanung $=$ The Balancing Problem in Multicriteria Decisions, Basics and Solution Method under Special Consideration of Regional Planning (in German), Peter Lang edition, Frankfurt am Main, 1996. 